\title{
Analysis of the interaction between risk factors for construction works on an example of the small experience of labourers
}

\author{
Krzysztof Kaczorek ${ }^{1 *}$, and Jarosław Malara ${ }^{2}$ \\ ${ }^{1}$ Warsaw University of Technology, The Faculty of Civil Engineering, 16 Lech Kaczyński Street \\ Warsaw 00-637, Poland \\ ${ }^{2}$ Cracow University of Technology, The Civil Engineering Faculty, 24 Warszawska Street \\ Cracow 31-155, Poland
}

\begin{abstract}
The successful course of any enterprise depends on materializing or non-risk factors. These factors affect not only the success or failure of the venture, but may also interact with each other. This paper describes the interactions between the factor "low experience of labourers" and six groups of other risk factors. The results of the analysis are presented in tabular form. The work was ended with conclusions and suggestions for further scientific and research work.
\end{abstract}

\section{Introduction and purpose of the work}

The successful course of any enterprise depends on materializing or non-risk factors. These factors affect not only the success or failure of the venture, but may also interact with each other. This leads to their mutual strengthening or weakening of the impact on the entire undertaking. Descriptions of such interactions can be found in literature sources from such areas as medicine [1] or social sciences [2]. Also in construction, this issue is increasingly being analyzed [3]. Determining the interaction between risk factors can be very useful, for example when estimating the execution times of construction works. It should be added that in such analysis one should focus primarily on strengthening the negative effects. This is an analogy to the principle known from the cost estimation of construction works, where the goal is to determine the value of the investment under the least favorable conditions. If the pessimistic scenarios do not materialize, the calculated cost surplus becomes an additional profit for the contractor. Similarly, when estimating the execution times of construction works, if the calculated values prove to be too large, the contractor will gain additional time to even check the work carried out or transfer the investment ahead of schedule. In this paper, the authors decided to present the issue on the example of the interaction between low experience of labourers and other risk factors.

\footnotetext{
* Corresponding author: k.kaczorek@il.pw.edu.pl
} 


\section{Determining the set of risk factors}

Before starting to determine the interaction between risk factors, a set of risk factors should be established that affect the time of construction work and will be included in the analysis. For this purpose, first identify the risk factors and then subject them to a qualitative analysis [4]. The mentioned activities, for Polish conditions, were carried out in publications [5, 6, 7]. The results from the above-mentioned works were merged and submitted to the opinion of building experts who manage large construction projects on a daily basis. What's more, the set of factors has been divided into thematic subsets. The effect of the activities carried out is shown in Table 1.

Table 1. Selected set of risk factors that will be analyzed in terms of interaction with the factor "low experience of labourers" [own elaboration].

\section{Risk factors related to logistics and resources.}

1.1. No possibility to use the required technology.

1.2. No work front.

1.3. Lack of workers.

1.4. Insufficient number of workers.

1.5. Insufficient number of machines.

1.6. Delays in the delivery of materials.

2. Risk factors related to administrative and legal aspects.

2.1. Difficulties with obtaining a permit for the execution of construction works.

2.2. Changes in the applicable law.

\section{Risk factors related to decision-making and communication.}

3.1. No investor's decision.

3.2. The dispute between the general contractor and the investor.

3.3. The dispute between the general contractor and the subcontractor.

3.4. Changes in the project at the investor's request.

4. Risk factors related to financial and payroll aspects.

4.1. Investor delays in payments.

4.2. Investor's difficulties in obtaining funds for investment financing.

\section{Risk factors related to improper construction management.}

5.1. Mistakes and incompatibilities in the project documentation.

5.2. Incorrect assumptions in the schedule.

5.3. Delays in previous works on the required working plot. 
5.4. Problems with the coordination of work.

6. Risk factors related to the construction environment.

6.1. Unfavorable weather conditions.

6.2. Unfavorable random event (eg accident, protests of the local community).

\section{Analysis of the interaction of the factor "low experience of labourers" with other risk factors}

After determining the set of risk factors that interact with the factor "low experience of labourers", it is necessary to begin describing the mutual impact for individual groups of risk factors. The analysis should take into account how other factors will reinforce the negative consequences of the low experience of labourers, which will translate into a decrease in the productivity of their work. In addition, it should be specified how the low experience of workers will strengthen the negative consequences or increase the severity of other risk factors [8].

\subsection{Interactions with risk factors related to logistics and resources}

\subsubsection{The influence of risk factors on the analyzed risk factor}

Improper logistic management can in extreme situations increase the small experience of labourers. This situation occurs if the persons supervising the investment do not have enough human resources or significant delays in providing it. In both cases, due to the limited availability of workers, a situation may arise where construction workers with no experience are employed under time pressure.

\subsubsection{The influence of the analyzed risk factor on the other risk factors}

The limited experience of construction workers is of moderate importance in the case of linking it to resource management. At the beginning, it should be pointed out that workers with little experience do not usually have tasks related to placing orders for materials. A separate issue is the limited decisiveness of these workers when deciding on personnel issues. The authors point out, however, that the employee's limited experience may cause inaccuracies and errors in informing decision-makers about the demand for resources. This is related to the lack of a proper assessment of the situation that is acquired through empirical experience.

\subsection{Interactions with risk factors related to administrative and legal aspects}

\subsubsection{The influence of risk factors on the analyzed risk factor}

Difficulties in obtaining a building permit can have a significant impact on the risk of limited experience of construction workers only to a limited extent, in specific conditions, 
at the beginning of the investment. Such a situation can only occur at the moment when the contractor, despite the contract concluded, can not start work on the planned date, and therefore delegates experienced workers to other tasks, with other projects. Then a deficit of construction workers arises, which can be supplemented with inexperienced staff. There are also changes in the law that can increase the percentage of less experienced workers. An example could be the abolition of the necessity to undergo periodic tests (including altitudes to work above $3 \mathrm{~m}$ ). The effects of legislative changes that would facilitate access to the possibility of taking up a job as a construction worker would certainly have an impact, in the initial phase of validity, on increasing the percentage of workers with little experience.

\subsubsection{The influence of the analyzed risk factor on the other risk factors}

The authors do not notice the impact of the limited experience of construction workers on the administrative procedure of the building permit obtained, or changes in the legal system. Interaction in this area does not take place.

\subsection{Interactions with risk factors related to decision-making and communication}

\subsubsection{The influence of risk factors on the analyzed risk factor}

It is possible to influence the making of wrong decisions and communication problems to increase the number of construction workers with little experience. Such a situation can only take place in the event of a dispute with workers. Making the wrong decisions may lead to the resignation of tasks performed by experienced workers and to fill staff shortages by less experienced people who may not be aware of the wrong decision making and communicating them by the decision-makers.

\subsubsection{The influence of the analyzed risk factor on the other risk factors}

The small experience of construction workers has no direct impact on the wrong investor's decisions or incorrect communication on his part. According to the authors, there is no interaction in this direction.

\subsection{Interactions with risk factors related to financial and payroll aspects}

\subsubsection{The influence of risk factors on the analyzed risk factor}

According to the work [8], the psychophysical condition of the workers is extremely important. One of the main factors that shapes the above-mentioned condition is stress. A small dose of stress usually has a positive effect on the attitude of the employee, makes him more worried about his work and tries to work better. Unfortunately, even a small excess of the "positive stress" dose is enough to drastically reduce the performance of the worried employee. In extreme situations, the employee may be paralyzed or be psychologically depressed. Since the payment terms are met by the investor, the payouts for labourers are 
often subject to timely payment. If the entity paying the remuneration directly to the employee (general contractor, subcontractor or investor) does not have sufficient funds, then a situation may arise where the employee is left without remuneration. Undoubtedly, such a situation has a very strong negative impact on workers and will translate into their dissociation, stress and, as a result, a decrease in productivity. The phenomenon will be additionally intensified if the worker has serious financial obligations (credit, family, care for someone / on something).

\subsubsection{The influence of the analyzed risk factor on the other risk factors}

The authors did not find a direct impact of the factor "low experience of labourers" on delays in making payments by the investor or obtaining funds for financing the entire project. Therefore, there is no interaction in this direction.

\subsection{Interactions with risk factors related to improper construction management}

\subsubsection{The influence of risk factors on the analyzed risk factor}

Improper management can affect the severity of the analyzed risk factor in two ways. The first considered situation can take place when the manager's mistakes are so serious that experienced workers, due to unfavorable working conditions, decide to resign from it, and staff shortages are supplemented with new, less experienced workers. The second situation occurs when inexperienced workers achieve low efficiency, while additional chaos associated with poor management (incorrect or contradictory orders from superiors) translates into an even greater decline in the efficiency of labourers [9].

\subsubsection{The influence of the analyzed risk factor on the other risk factors}

Inexperienced labourers can only affect some of the identified risk factors within the group related to improper construction management. Emphasize the impact on the possibility of delays on previous work plots and problems with the coordination of work. In both cases, the workers' small experience can activate the threats described by the aforementioned risks.

\subsection{Interactions with risk factors related to the construction environment}

\subsubsection{The influence of risk factors on the analyzed risk factor}

According to the authors, neither unforeseen events nor weather conditions affect the experience of labourers. Risk factors related to the construction environment are largely random, hence the lack of interaction between them and experience. However, they can have a very large impact on the severity of the effects of low experience, which is the low productivity of workers. Unfavorable weather conditions (rainfall, very low or very high temperature values, significant wind intensity) practically always cause an additional drop in employee productivity. This phenomenon is relatively unaffected by workers performing 
work inside the building, when at least a closed shell is obtained. However, the impact of random events will primarily depend on the type of individual events. For example, an accident can significantly lower the brigade's morale, and protests of the local community, unless they take place at the place of work, will not further reduce workers' productivity.

\subsubsection{The influence of the analyzed risk factor on the other risk factors}

The low experience of labourers usually translates into an increase in recorded accidents on the construction site. These are often derived from the lack of prudence, bravery, willingness to facilitate work in a prohibited way, i.e. factors deriving from low experience. What's more, inexperienced workers usually less secure the robots against the negative impact of adverse weather conditions, thereby intensifying their impact on the progress of works.

\section{Tabular summary of results}

The results of the analysis from point 3 of this paper are presented in a synthetic way in the Table 2. To assess the mutual impact, linguistic variables were used: none, very low, low, medium, high, very high.

Table 2. Summary of analysis's results [own elaboration].

\begin{tabular}{|c|c|c|}
\hline Group of risk factors. & $\begin{array}{c}\text { Influence on analized risk } \\
\text { factor. }\end{array}$ & $\begin{array}{c}\text { Influence of analized } \\
\text { factor on the other } \\
\text { factors. }\end{array}$ \\
\hline $\begin{array}{c}\text { Risk factors related to } \\
\text { logistics and resources. }\end{array}$ & High. & Medium. \\
\hline $\begin{array}{c}\text { Risk factors related to } \\
\text { administrative and legal } \\
\text { aspects. }\end{array}$ & High. & None. \\
\hline $\begin{array}{c}\text { Risk factors related to } \\
\text { decision-making and } \\
\text { communication. }\end{array}$ & High. & None. \\
\hline $\begin{array}{c}\text { Risk factors related to } \\
\text { financial and payroll } \\
\text { aspects. }\end{array}$ & High. & None. \\
\hline
\end{tabular}




\begin{tabular}{|c|c|c|}
\hline $\begin{array}{c}\text { Risk factors related to } \\
\text { improper construction } \\
\text { management. }\end{array}$ & Very high. & Medium. \\
\hline $\begin{array}{c}\text { Risk factors related to the } \\
\text { construction } \\
\text { environment. }\end{array}$ & Very high. & Very high. \\
\hline
\end{tabular}

\section{Summary and Conclusions}

This paper analyzes the interactions of the risk factor "low experience of labourers" with other risk factors, which most often occur in the conditions occurring at construction sites with which the authors have contact. Risk factors were divided into six groups, which allowed to improve the analysis process and increase the transparency of its results. The results themselves were presented in the form of linguistic variables. The analysis carried out shows clearly that the factors interact with each other. Some interactions are very intense, which shows that the current insufficient intense handling of this issue was wrong. Similar analyzes should be conducted for other risk factors. What's more, thanks to the use of linguistic variables, it is possible to use the results of the analysis in fuzzy decision models [10]. Such application of the analysis will translate into a significant improvement in the forecasting of disturbances and difficulties related to conducting construction works.

\section{References}

1. Ż. Fiodorenko-Dumas, M. Paprocka-Borowicz, M. Rabczyński, M. MajewskaPulsakowska, Chirurgia Polska, 15(1), 33 (2013)

2. K. Okulicz-Kozaryn, K. Bobrowski, Prace Przeglądowe, Alkoholizm i Narkomania, 21(2), 173 (2008)

3. K. Kaczorek, J. Kulejewski, N. Ibadov. Materiały Budowlane (to be published)

4. K. Kaczorek, Czasopismo Techniczne, 10, 103 (2017)

5. H. Anysz, A. Zbiciak, Autobusy: Technika, Eksploatacja, Systemy Transportowe, 3, 963 (2013)

6. A. Leśniak, E. Plebankiewicz, Zeszyty Naukowe Wyższej Szkoły Oficerskiej Wojsk Lądowych, 157(3), 332 (2010)

7. A. Leśniak, Czasopismo Techniczne, 2, 57 (2012)

8. E. Plebankiewicz, M. Juszczyk, J. Malara, Przegląd Naukowy - Inżynieria i Kształtowanie Środowiska, 65, 271 (2014)

9. M. Krzemiński, Procedia Engineering, 208, 109 (2017)

10. N. Ibadov, J. Kulejewski, Czasopismo Techniczne, 107(2), 231 (2010) 